\title{
Sensitive Skin in China
}

\author{
Miranda A. Farage $^{1 *}$, Christian P. Mandl ${ }^{2}$, Enzo Berardesca ${ }^{3}$, Howard I. Maibach ${ }^{4}$ \\ ${ }^{1}$ The Procter \& Gamble Company, Winton Hill Business Center, Cincinnati, USA; ${ }^{2}$ The Procter \& Gamble Company, Schwalbach, \\ Germany; ${ }^{3}$ San Gallicano Dermatological Institute, Rome, Italy; ${ }^{4}$ Department of Dermatology University of San Francisco, Medical \\ School, San Francisco, USA. \\ Email: ${ }^{*}$ farage.m@pg.com
}

Received May $10^{\text {th }}, 2012$; revised June $15^{\text {th }}, 2012$; accepted June $29^{\text {th }}, 2012$

\begin{abstract}
Background: Many consumers in the USA and Europe define themselves as having sensitive skin, a phenomenon whose etiology appears to include both physiological and psychosocial factors. Objectives: Sensitive skin data from the developing world is sparse. This study evaluates the prevalence and characteristics of sensitive skin in China and compares data collected to existing data from the western world. Patients/Materials/Methods: A total of 408 Chinese women voluntarily completed a survey on sensitive skin. Results: Some degree of skin sensitivity was claimed by 94 (23\%) of respondents; most (90.4\%) said their skin was only slightly or moderately sensitive. Facial sensitivity was claimed by $21 \%$ of Chinese women, sensitivity of the body surface by $9 \%$ and genital sensitivity by only $6 \%$. Small numbers of respondents reported a history of skin allergy (3\%) or a familial history of sensitive skin (2\%). Many reported making buying decisions based on product claims. Conclusions: Only 23\% of Chinese women claimed any degree of sensitive skin, a prevalence substantially lower than that observed in most Western countries. Sensitivity of the genital skin, in particular, was dramatically lower, suggesting at least some cultural component to perceptions of sensitive skin.
\end{abstract}

Keywords: Sensitive Skin; Genital Skin; Irritation; Skin Sensitivity; Stinging; Erythema; Feminine Hygiene; Fabrics; Sensory

\section{Introduction}

Many consumers in industrialized countries today define themselves as having "sensitive skin", reporting unpleasant dermatological sensations to common exposures like weather conditions or health and beauty products, the latter despite extensive premarket testing which had seemingly confirmed a lack of irritant potential. The condition is typically self-diagnosed, with sensory manifestations which include burning, stinging, and itching with visual manifestations such rashes, erythema, and papules. Many patients, however, report sensory hyperstimulation without any measurable cutaneous manifestation.

An authoritative definition of sensitive skin is elusive. Numerous testing methodologies have attempted to define the physiological basis for these complaints, includeing visual inspection, transepidermal water loss (TEWL), hydration of the stratum corneum, erythema, blood flow, and surface $\mathrm{pH}$. Subjective effects are more difficult to study; and no consistent correlation between the degree of perceived sensitivity and any measurable physiological parameters has been established.

The diversity of both the causes of sensitive skin and its manifestations implies a multifactorial syndrome in *Corresponding author. which numerous components, both intrinsic and extrinsic, may play significant roles. Gender is an obvious contributor; women report sensitive skin significantly more often than men [1-6]. Age may also be a factor, as well as skin type, concurrent dermatological diseases, or a history of allergy or atopy. Ethnicity also may influence skin sensitivity, as ethnicity and skin type strongly influence both skin structure and function [7].

The anatomic location in question may also be influential. Skin structure differs at different anatomic sites [7]. Green found differences in sensory responses to capsaicin between the face and the forearm [8]; Britz and Maibach [9] and Elsner [10] observed that vulvar skin exhibits chemical-specific differences from forearm skin with regards to reactivity to a variety of known chemical irritants.

Genital skin, particularly, differs structurally and histologically from skin in other anatomical areas and those differences affect skin sensitivity. While no association between sensitive skin and ethnic background was found at the face or body, sensitive skin of the genital region was significantly higher in African Americans than in Caucasians, Asians, or Hispanics [1]. Similarly, while skin on the face and body showed no gender-specific dif- 
ferences in sensitivity, the genital area did: $58.1 \%$ of women report skin sensitivity in the genital area as compared to $44.2 \%$ of men [1]. Older people are more likely to claim sensitivity of genital skin than younger [1].

Geographical differences have also been observed in the prevalence of skin sensitivity. Geographical disparity may stem from natural factors like weather patterns, but some scientists have proposed that the geographic differences may represent a cultural phenomenon related to media and advertising wherein it has become culturally fashionable to claim sensitive skin.

Cultural factors do seem to play a role in the phenomenon of skin sensitivity. The percentage of people who perceive themselves to have sensitive skin appear to be on the increase, particularly among men [11], probably related to an increase in marketing of sensitive-skin products to men which may make it more culturally acceptable for men to claim sensitive skin [12]. The fact that the majority are women in the industrialized world defies the perception as a minority complaint and tends to support at least some psychosocial component.

Surveys have been a popular method for collecting epidemiological data on sensitive skin, a largely self-identified condition, in various populations. Although surveys across Europe, Asia, and North and South America have consistently shown that the majority of the populations of industrialized societies (and more women than men) believe themselves to have sensitive skin (Table 1),

Table 1. Percentage of overall skin sensitivity across the world.

\begin{tabular}{|c|c|c|c|c|c|c|c|}
\hline \multirow[b]{2}{*}{ Country } & \multirow[b]{2}{*}{ Year } & \multicolumn{6}{|c|}{ Reported sensitivity (\%) } \\
\hline & & Population & $\begin{array}{c}\text { Overall } \\
\text { sensitivity }^{* *}\end{array}$ & $\begin{array}{c}\text { Very } \\
\text { sensitive }\end{array}$ & $\begin{array}{c}\text { Moderately } \\
\text { sensitive }\end{array}$ & $\begin{array}{c}\text { Slightly } \\
\text { sensitive }\end{array}$ & Reference \\
\hline China & 2009 & $\begin{array}{l}F \\
18-65 \\
N=408\end{array}$ & 23 & 2 & 5 & 16 & Present study \\
\hline Global & 2010 & $\begin{array}{l}\mathrm{F} \\
\mathrm{N}=191\end{array}$ & 84 & 10 & 38 & 36 & $\begin{array}{c}\text { Farage, data } \\
\text { yet unpublished }\end{array}$ \\
\hline Asia & 2010 & $\begin{array}{l}M \text { and } F \\
18-65 \text { years } \\
N=72\end{array}$ & 90 & NA & NA & NA & \\
\hline Europe & 2010 & $\begin{array}{l}\mathrm{M} \text { and } \mathrm{F} \\
18-65 \text { years } \\
\mathrm{N}=94\end{array}$ & 88 & NA & NA & NA & \\
\hline Latin America & 2010 & $\begin{array}{l}\mathrm{M} \text { and } \mathrm{F} \\
18-65 \text { years } \\
\mathrm{N}=78\end{array}$ & 85 & NA & NA & NA & \\
\hline North America, OH & 2010 & $\begin{array}{l}\mathrm{M} \text { and } \mathrm{F} \\
18-65 \text { years } \\
\mathrm{N}=122\end{array}$ & 78 & NA & NA & NA & \\
\hline North America, all other & 2010 & $\begin{array}{l}\mathrm{M} \text { and } \mathrm{F} \\
18-65 \text { years } \\
\mathrm{N}=71\end{array}$ & 77 & NA & NA & NA & \\
\hline USA (MS) & 2010 & $\begin{array}{l}\mathrm{F} \\
18-68 \text { years } \\
\mathrm{N}=57\end{array}$ & 87.5 & NA & NA & NA & $\begin{array}{l}\text { Farage, data } \\
\text { yet unpublished }\end{array}$ \\
\hline Europe (total) & 2007 & $\begin{array}{l}M \text { and } F \\
\geq 15 \text { years } \\
N=4506\end{array}$ & 74.7 & 13 & 25.1 & 36.6 & {$[3]$} \\
\hline Greece & 2007 & $\begin{array}{l}M \text { and } F \\
\geq 15 \text { years } \\
N=500\end{array}$ & 70 & 8.6 & $22.4^{*}$ & $29^{*}$ & [3] \\
\hline Germany & 2007 & $\begin{array}{l}M \text { and } F \\
\geq 15 \text { years } \\
N=500\end{array}$ & 59 & $15.8^{*}$ & $20^{*}$ & 23.2 & [3] \\
\hline Belgium & 2007 & $\begin{array}{l}M \text { and } F \\
\geq 15 \text { years } \\
N=500\end{array}$ & 60 & $10^{*}$ & $16^{*}$ & $4^{*}$ & {$[3]$} \\
\hline Switzerland & 2007 & $\begin{array}{l}M \text { and } F \\
\geq 15 \text { years } \\
N=500\end{array}$ & 59 & $13^{*}$ & $18^{*}$ & $28^{*}$ & [3] \\
\hline Spain & 2007 & $\begin{array}{l}M \text { and } F \\
\geq 15 \text { years } \\
N=500\end{array}$ & 88 & $13^{*}$ & $20^{*}$ & $55^{*}$ & [3] \\
\hline
\end{tabular}




\section{Continued}

\begin{tabular}{|c|c|c|c|c|c|c|c|}
\hline Italy & 2007 & $\begin{array}{l}M \text { and } F \\
\geq 15 \text { years } \\
N=500\end{array}$ & 90.6 & $17.4^{*}$ & $37.2^{*}$ & $36^{*}$ & [3] \\
\hline Portugal & 2007 & $\begin{array}{l}M \text { and } F \\
\geq 15 \text { yrs } \\
N=500\end{array}$ & 86 & $16.2^{*}$ & $13.4^{*}$ & $56.4^{*}$ & [3] \\
\hline France & 2007 & $\begin{array}{l}M \text { and } F \\
\geq 15 \text { yrs } \\
N=1006\end{array}$ & 82 & $12.1 \%{ }^{*}$ & $39.9 \%{ }^{*}$ & $30 \%{ }^{*}$ & [3] \\
\hline \multirow[t]{2}{*}{ USA $(\mathrm{OH})$} & 2006 & $\begin{array}{l}\text { M } 16 \% \\
\text { F } 84 \% \\
\text { Mean Age } 39 \text { yrs } \\
\text { N = } 1039\end{array}$ & 68.4 & 4.9 & 23 & 40.5 & {$[1]$} \\
\hline & & F only & 69.0 & NA & NA & NA & \\
\hline Japan & 2006 & $\begin{array}{l}\mathrm{F} \\
\text { Adults } \\
\mathrm{N}=\mathrm{NA}\end{array}$ & $\sim 50$ & NA & NA & NA & [16] \\
\hline Greece & 2005 & $\begin{array}{l}\mathrm{F} \\
\text { Age } 18-45 \mathrm{yrs} \\
\mathrm{N}=25\end{array}$ & 64 & 0 & 16 & 48 & [17] \\
\hline France & 2004-2005 & $\begin{array}{l}F \\
18-85 y r s \\
N=400\end{array}$ & 85.4 & 30.5 & NA & NA & [18] \\
\hline Italy & 2004 & $\begin{array}{l}\text { M } 11.5 \% \\
\text { F } 88.5 \% \\
18-80 y r s \\
N=2101\end{array}$ & $59.9 \mathrm{~F}$ & NA & NA & NA & [19] \\
\hline \multirow[t]{2}{*}{ France } & March, 2004 & $\begin{array}{l}\text { M } 41 \% \\
F 59 \% \\
\geq 15 \text { yrs } \\
N=1006\end{array}$ & 80.3 & 11.9 & 39.8 & 28.5 & {$[2,5]$} \\
\hline & March 2004 & $\begin{array}{l}F \\
\geq 15 \text { yrs } \\
N=594\end{array}$ & 85.46 & 14.91 & 44.36 & 26.2 & {$[2,5]$} \\
\hline France & July, 2004 & $\begin{array}{l}\text { M } 48 \% \\
\text { F } 52 \% \\
\geq 15 \text { yrs } \\
N=1001\end{array}$ & 86.3 & 20.7 & 38.2 & 27.5 & [5] \\
\hline France & July, 2004 & $\begin{array}{l}F \\
\geq 15 \mathrm{yrs} \\
\mathrm{N}=521\end{array}$ & 91.17 & 28.21 & 41.07 & 21.88 & [5] \\
\hline \multirow[t]{2}{*}{ Germany } & 2001 & $\begin{array}{l}\text { M } 39 \% \\
\text { F } 61 \% \\
\text { Mean age } 46 \text { yrs } \\
\text { N = 420 }\end{array}$ & 75. & 17.6 & 29.5 & 28.1 & {$[6]$} \\
\hline & & $\begin{array}{l}\text { F only } \\
\mathrm{N}=258\end{array}$ & 82.6 & 19.0 & 29.5 & 28.1 & [6] \\
\hline \multirow[t]{2}{*}{ UK } & 2001 & $\mathrm{M}$ and $\mathrm{F}$ & 49.56 & 8.12 & NA & NA & [4] \\
\hline & & $\begin{array}{l}\text { F only } \\
\geq 18 \text { yrs } \\
N=2046\end{array}$ & $51 \%$ & 10 & NA & NA & [4] \\
\hline France & 2000 & $\begin{array}{l}\mathrm{F} \\
\text { Adult } \\
\mathrm{N}=310\end{array}$ & 90 & $\sim 25$ & NA & NA & [20] \\
\hline France & 2006 & $\begin{array}{l}\mathrm{F} \\
\text { Adult } \\
\mathrm{N}=5074\end{array}$ & 61 & NA & NA & NA & [21] \\
\hline USA (CA) & 1998 & $\begin{array}{l}F \\
18-54 \text { yrs } \\
N=811\end{array}$ & 52 & NA & NA & NA & [22] \\
\hline
\end{tabular}

$\bar{*}$ Percentages not reported but interpreted from bar graphs; ${ }^{* *}$ Overall sensitivity percentages totals all respondents who reported any degree of sensitivity; $\mathrm{F}=$ female, $\mathrm{M}=$ male. 
no data has previously been collected with regard to the experience of sensitive skin in the rapidly developing nation of China.

\section{Methods}

The Chinese data presented here were obtained in the context of a study that evaluated the needs of sensitiveskin consumers in China. The survey assessed multiple parameters of perception of sensitive skin in Chinese women. Subjects were aged 18 - 65. Of subjects who completed surveys, $84.3 \%$ were between 25 and 54 years of age, $9.1 \%$ were 24 or younger, and $6.6 \%$ were 55 and older. Specific questions addressed the relationship of skin sensitivity to intrinsic factors like age and anatomic site as well as to environmental exposures, product use, and product buying decisions.

\section{Results}

\subsection{Overall Skin Sensitivity}

A total of 408 surveys were collected. Of those respondents, $314(77 \%)$ denied sensitive skin, while 65 respondents $(16 \%)$ claimed they had slightly sensitive skin, 20 respondents $(5 \%)$ claimed they had moderately sensitive skin, and 9 respondents (2\%) claimed they had very sensitive skin. Only $3 \%$ of respondents stated that they have skin allergies confirmed by a doctor, and only $2 \%$ of respondents claimed a family member also had sensitive skin. Eleven percent of the respondents claimed not to buy products with specific ingredients because of potential irritation.

An additional 128 surveys were collected exclusively from subjects who perceived themselves to have sensitive skin, yielding a total of 222 sensitive-skin subjects.

There were no directional differences between the three body areas in perceived duration of skin sensitivity. Overall there was a slight correlation between the degree of sensitive skin and its duration, particularly with regard to genital skin. When the duration of skin sensitivity was evaluated only in those who claimed sensitivity, no difference was observed between body areas and just over a third of the respondents claimed to have sensitive skin for less than 6 months. Although not significant, severity of sensitive skin tended to decrease over time in all three body areas evaluated. Only skin sensitivity in the facial area increased.

The majority of the 408 respondents from the general population, $79 \%$, stated that their menstrual cycle was regular, 3\% stated their cycle was not regular and they were not close to menopause, $2 \%$ stated their cycle was not regular but that they were close to menopause, $2 \%$ stated they were experiencing menopausal symptoms, $14 \%$ stated they no longer have menstrual cycles, and none of the respondents stated they were pregnant. None of the respondents were taking hormone replacement therapy (HRT), while $97.9 \%$ stated they were not experiencing menopausal symptoms and the remaining $2.1 \%$ stated they had symptoms but were not on HRT.

\subsubsection{Facial Skin}

Of the 408 respondents 324 (79\%) claimed to be not sensitive in the facial area, while 50 respondents $(12 \%)$ claimed to be slightly sensitive, 22 respondents $(5 \%)$ claimed to be moderately sensitive, and 12 respondents (3\%) claimed to be very sensitive.

Respondents were asked "Why you think you have sensitive facial skin?" The most common answer among those that claimed to have sensitive skin was due to topical products causing visual side effects $(35.1 \%)$. Another $29.3 \%$ stated it was due to sensory side effects by topical products, $29.8 \%$ stated it was due to the weather, $2.0 \%$ stated rough fabrics to be the cause and $3.9 \%$ stated other reasons.

Of the respondents who claimed to have sensitive skin, $39.5 \%$ said they have had sensitive skin for less than 6 months, $7.3 \%$ said 6 to 11 months, $27.8 \%$ said 1 to 5 years, $7.3 \%$ said 6 to 10 years, and $18 \%$ said 10 years or more. Respondents were also asked if their sensitive skin has changed over time and $43.4 \%$ stated they were either much less or a little less sensitive now, $46.8 \%$ stated there was no change and $9.8 \%$ stated they were either much more or a little more sensitive now. Answers were scored as +2 for much more sensitive over time, +1 for a little more, 0 for no change, -1 for a little less sensitive over time, and -2 for much less sensitive. The average change in severity of sensitive facial skin was -0.49 $( \pm 0.90)$, a value that indicates slight improvement of overall facial skin sensitivity over time.

\subsubsection{Body}

Of the 408 respondents, 370 (91\%) denied sensitivity of the body area, while 26 respondents $(6.0 \%)$ claimed to be slightly sensitive, 9 respondents (2\%) claimed to be moderately sensitive, and 3 respondents (1\%) claimed to be very sensitive.

When sensitive skin respondents were asked why they have sensitive skin of the body, the most common answer was weather (44.3\%). Another $21.6 \%$ claimed to be due to rough fabrics, $9.1 \%$ was due to visual effects, $19.3 \%$ due to sensory effects, and $5.7 \%$ by other causes.

Of the respondents claiming sensitive skin of the body, $34.1 \%$ stated they have had it for less than 6 months, $6.8 \%$ stated 6 to 11 months, $27.3 \%$ stated 1 to 5 years, $6.8 \%$ stated 6 to 10 years, and $25 \%$ stated 10 years or more. Twenty-five percent of respondents stated their skin of the body was either much less or little less sensitive now, $61.4 \%$ stated there was no change, and $13.6 \%$ 
stated it was either much more or little more sensitive now. The average change in severity of sensitive skin of the body was $-0.22( \pm 0.81)$, a value that indicates a slight decrease in skin sensitivity on the body, although not as much of a decrease as was observed with regards to facial skin.

\subsubsection{Genital Area}

Of the 408 respondents, 383 (94\%) denied sensitivity in the genital area, while 18 respondents (4\%) claimed to be slightly sensitive, 4 respondents $(1 \%)$ claimed to be moderately sensitive, and 3 respondents $(1 \%)$ claimed to be very sensitive.

Among those who claimed sensitivity of genital skin, the most common cause was reported to be rough fabrics (42.5\%). Weather was blamed by $22.5 \%, 12.5 \%$ claimed topical products were to blame (causing visual effects), and 20\% named topical products (causing sensory effects). Some $2.5 \%$ claimed other causes.

Of the respondents who claimed to have sensitive genital skin, 37.5\% stated they have had it for less than 6 months, $15 \%$ stated 7 to 11 months, $22.5 \%$ stated 1 to 5 years, $5 \%$ stated 6 to 10 years, and $20 \%$ stated 10 years or more. When asked about change in skin sensitivity, $47.5 \%$ of respondents said their skin is much less or a little less sensitive now, $47.5 \%$ stated no change, and $5 \%$ reported that their skin was much more or a little more sensitive now. The average change in severity of sensitive genital skin was $-0.68( \pm 0.92)$, indicating improvement of skin sensitivity in the genital area that exceeds that of both the facial skin and the body.

\subsection{Age Distribution}

Individuals between the ages of 18 - 65 were chosen and the average age of respondents in each perceived sensitivity degree were similar average ages. Respondents who claimed to not have sensitive skin in general were an average age of 39 years old, those who claimed to be slightly sensitive were 38 years old, those who claimed moderate sensitivity were 40 years old, and those who claimed to be very sensitive were 38 years old. The distribution of sensitive skin with respect to age was similar between all age groups and no difference was observed between any age group with the perceived degree of sensitive skin at any body site. Women in the 55 - 65 age group had the highest percentage of respondents who claimed they did not have sensitive skin in all three body areas.

\subsection{Factors Attributed to Skin Irritation}

\subsubsection{Environmental Factors}

The sun and hot weather caused skin irritation $(34.5 \%$, $31.2 \%$ respectively) and breakouts $(21.6 \%, 22.6 \%$ re- spectively) more often any other weather condition. Fabrics were the least likely cause of irritation with only $11.6 \%$ of the population claiming it. Most other environmental factors caused irritation in $15 \%$ to $20 \%$ of the population. Only $16.6 \%$ of women claimed their menstrual cycle ever caused them to have skin irritation. For most the environmental factors, greater than $80 \%$ of respondents who claimed to have irritation caused by that factor had irritation only sometimes.

\subsubsection{Household, Health, and Beauty Products}

Seven products that were perceived as irritating by less than $5 \%$ of the respondents as follows: shampoo/conditioner, deodorants, antiperspirants, household cleaners, dishwashing liquid, laundry detergent, and fabric softeners. Eight products perceived to cause irritation by greater than $10 \%$ of the respondents as follows: hair colorants, facial cosmetics, facial moisturizers, facial astringents, facial cleanser, body moisturizers, sunscreen, and powder/talc (Figure 1). All the products used directly on the face were perceived as irritating in greater than $10 \%$ of the population. Powder/talc maybe more likely to be perceived to cause irritation than deodorant because in the eastern hemisphere powder is used as a deodorant more than other products. Household products were not frequently perceived as a source of irritation. Laundry detergent was the most likely household product to be perceived as a source of irritation (4.9\%); the least likely was dishwashing liquid (1.8\%).

\subsubsection{Personal-Hygiene Products}

Respondents were asked whether certain feminine products used on the genitalia caused irritation (redness, burning or itching). The products most likely to be perceived as a source of irritation were clothing, toilet paper, and feminine wipes. The two products with the most respondents claiming perceived irritation, feminine wipes and incontinence pads, however were most often defined as only sometimes causing irritation (Figure 2). Menstrual pads, pantiliners, tampons, deodorants/antiperspirants and douching products were used by less than $40 \%$ of the respondents. Menstrual pads and pantiliners were the least likely products to be perceived to cause irritation on a regular basis. No respondent perceived menstrual pads or pantiliners to always or frequently be a source of irritation, though respondents did claim that menstrual pads $(3.7 \%)$ and pantiliners $(1.3 \%)$ did sometimes seem to cause irritation.

\section{Discussion}

The study population was relatively large with 536 respondents and composed entirely of adults Chinese women. Although comparison data cannot be collected for 


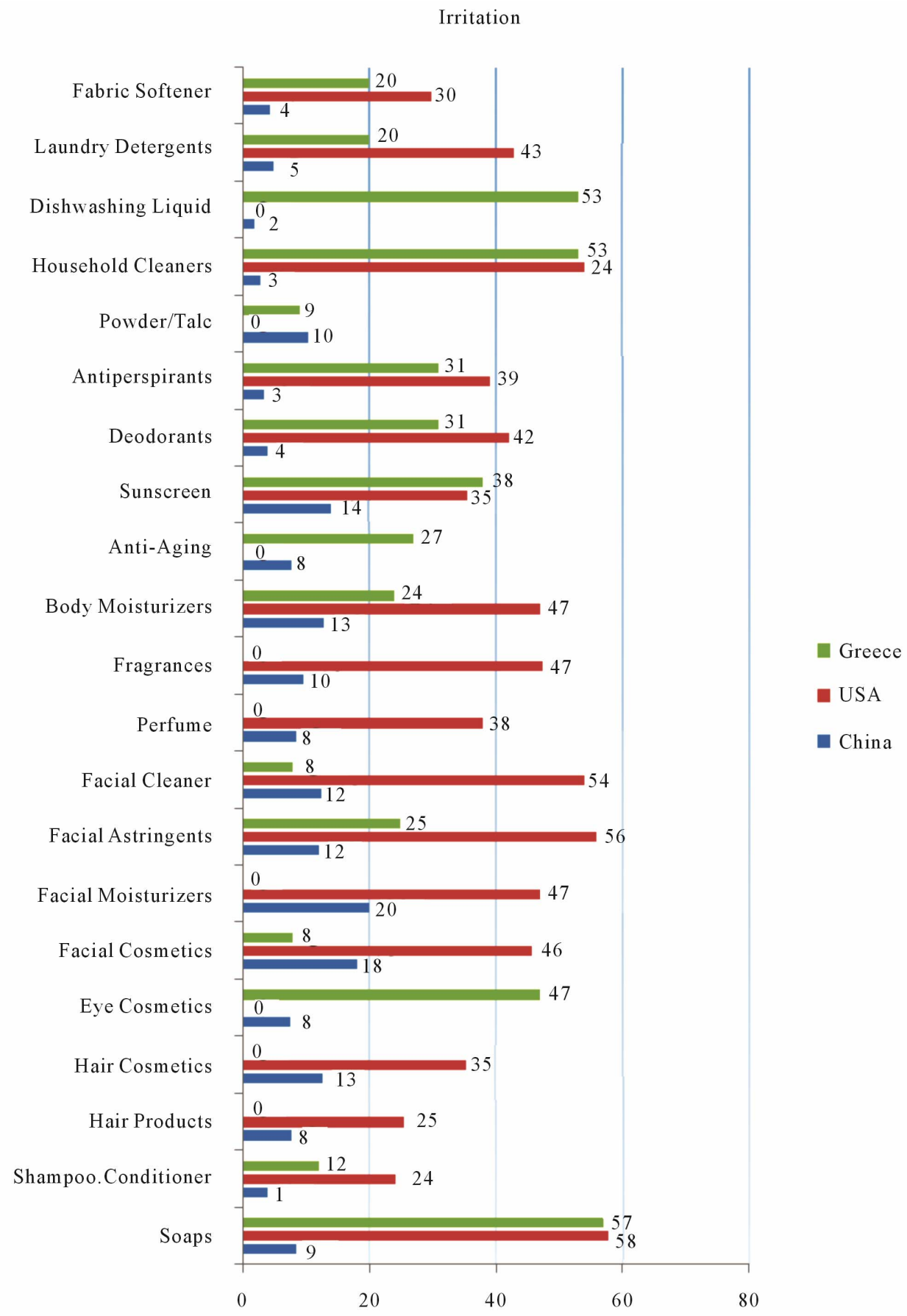

Figure 1. Percent of females reporting irritation caused by products.

gender or ethnicity, since the questionnaire employed was similar to our previous study conducted in Cincinnati, Ohio, the results can still be effectively compared to the US data.

The majority of the studies conducted globally have shown that greater than $50 \%$ of individuals have sensitive skin (Table 1), with percentages of women who claim sensitive skin across the globe varying from about $60 \%$ to $90 \%$. The present study found that only $23 \%$ of
Chinese women claim to have sensitive skin, demonstrably lower than lower than that found thus far in other countries.

When the Chinese data is compared to our prior US data there is a clear difference in the perceived skin sensitivity. In the study conducted in Cincinnati, Ohio, in $2009,68.4 \%$ of 1039 people surveyed claimed to have some degree of sensitivity, compared to $23 \%$ in China [1]. Facial skin sensitivity also showed different findings: 
$21 \%$ claimed to have some degree of sensitivity of facial skin in China respectively, compared to $77.3 \%$ in our prior study [1] and as much as $85 \%$ of women in France (Table 2). A prior study in San Francisco evaluated comparative skin sensitivity in specific ethnic groups, including 200 Asians and found that $52 \%$ claimed to have sensitive facial skin. This finding is closer to the overall rate for Chinese women of $23 \%$ than the overall US average obtained in our prior study of $77.3 \%$ [1]. However, the San Francisco study found similar prevalence with a 52\% prevalence of sensitive skin overall, a difference which could result from the different wording of the questions asking women to define their skin as sensitive. In addition, the San Francisco study was one of the earliest epidemiological studies performed (2001) and self-reported sensitive skin in industrialized countries has steadily risen (Table 1).

The most dramatic differences could be seen in the body and genital areas, where the US population shows that $60.7 \%$ and $56.3 \%$ have some degree of sensitivity in those areas respectively compared to $9 \%$ and $6 \%$ respectively for the Chinese population [1] (Table 3). Genital skin differs from exposed skin in other body areas, in being dramatically thinner [13] and to varying degrees

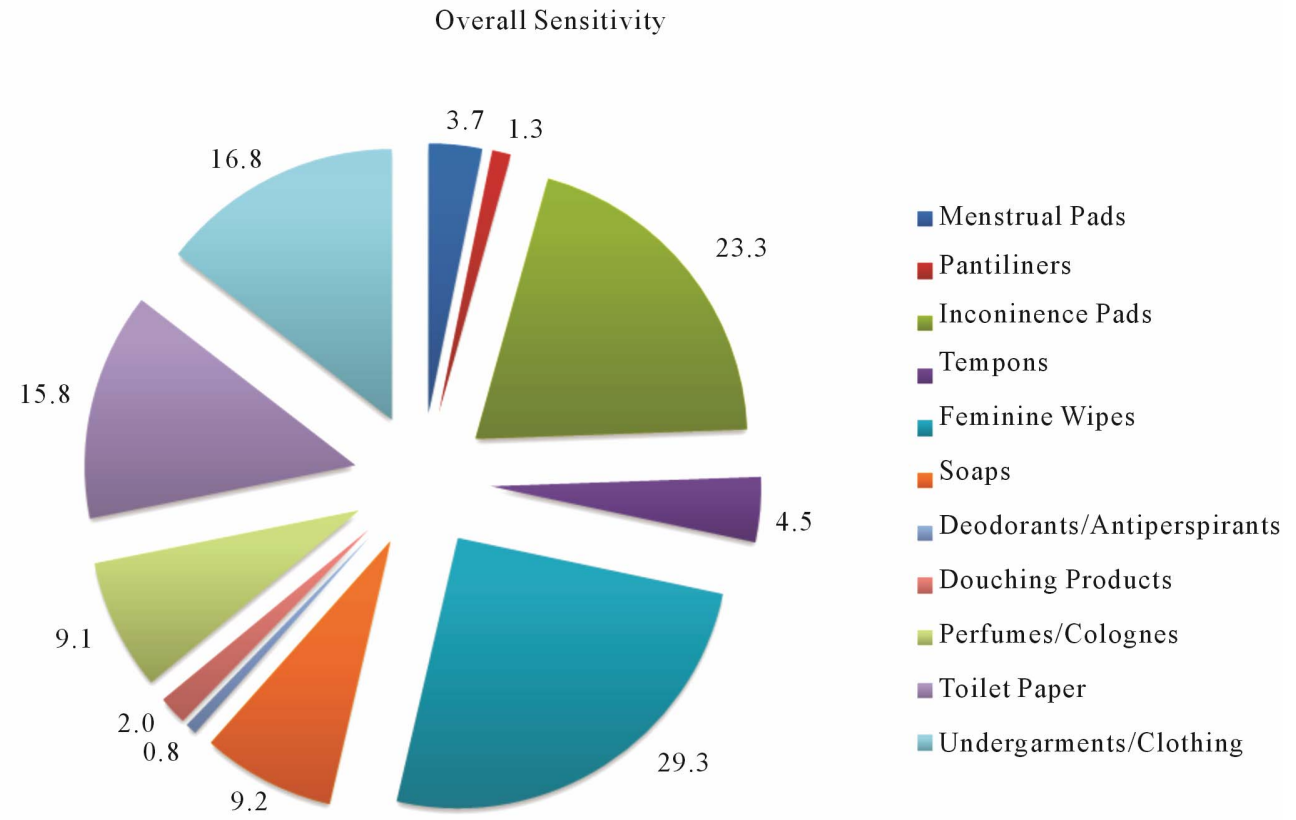

Figure 2. Frequency (\%) of irritation (redness, burning, itching) in the genital area following the use of different products (China).

Table 2. Percent of women with self-declared sensitive skin at the face.

\begin{tabular}{|c|c|c|c|c|c|c|c|}
\hline \multirow[b]{2}{*}{ Country } & \multirow[b]{2}{*}{ Year } & \multicolumn{6}{|c|}{ Reported Sensitivity (\%) } \\
\hline & & Population & Overall sensitivity & Very sensitive & Moderately sensitive & Slightly sensitive & Reference \\
\hline China & 2009 & $\begin{array}{l}F \\
18-65 \text { yrs } \\
N=408\end{array}$ & 21.0 & 3.0 & 5.0 & 12.0 & Present data \\
\hline USA (Ohio) & 2006 & $\begin{array}{l}\mathrm{F} \\
\text { Adults } \\
\mathrm{N}=1039\end{array}$ & 77.3 & 4.9 & 23.0 & 40.5 & [1] \\
\hline France & 2004-2005 & $\begin{array}{l}\mathrm{F} \\
18-85 \mathrm{yrs} \\
\mathrm{N}=400\end{array}$ & 85.4 & 30.5 & NA & NA & [18] \\
\hline UK & 2001 & $\begin{array}{l}F \\
\geq 18 \text { yrs } \\
N=2036\end{array}$ & 34.6 & NA & NA & NA & [4] \\
\hline USA (California) & 1998 & $\begin{array}{l}\mathrm{F} \\
18-54 \mathrm{yrs} \\
\mathrm{N}=811\end{array}$ & 52 & NA & NA & NA & [22] \\
\hline
\end{tabular}

$\mathrm{F}=$ Female, $\mathrm{NA}=$ Data not available. 
Table 3. Percent of individuals with self-declared sensitive skin at specific anatomic locations.

\begin{tabular}{|c|c|c|c|c|c|c|}
\hline \multirow[b]{2}{*}{ Country } & \multirow[b]{2}{*}{ Year } & \multirow[b]{2}{*}{ Population } & \multicolumn{3}{|c|}{ Anatomic Location (\%) } & \multirow[b]{2}{*}{ Reference } \\
\hline & & & Face & Body & Genitals & \\
\hline China & 2009 & $\begin{array}{l}F \\
18-65 y r s \\
N=408\end{array}$ & 21 & 9 & 6 & Current study \\
\hline USA & 2009 & $\begin{array}{l}\mathrm{M}(16 \%) \\
\mathrm{F}(84 \%) \\
\text { Mean age } 35.1 \mathrm{yrs} \\
\mathrm{N}=1039\end{array}$ & 77.3 & 60.7 & 56.3 & [1] \\
\hline France & 2008 & $\begin{array}{l}M \text { and } F \\
\geq 15 \text { yrs } \\
N=1011\end{array}$ & NA & $\begin{array}{l}\text { Scalp } \\
47.4 \mathrm{~F} \\
40.8 \mathrm{M}\end{array}$ & NA & {$[23]$} \\
\hline France & $2004-2005$ & $\begin{array}{l}F \\
18-85 y r s \\
N=400\end{array}$ & 85 & $\begin{array}{l}58 \text { Hands } \\
36 \text { Scalp } \\
34 \text { Feet } \\
27 \text { Neck } \\
23 \text { Torso } \\
21 \text { Back }\end{array}$ & NA & {$[18]$} \\
\hline
\end{tabular}

$\mathrm{F}=$ Female, $\mathrm{M}=$ Male, $\mathrm{NA}=$ Data not available.

non-keratinized and occluded. These differences may make the genital area in women more permeable than exposed keratinized skin [14].

Our finding that skin sensitivity between the US and Chinese population of women to have the most dramatic difference observed is consistent with prior observation that findings related to genital skin tend to differ from those at other body sites. Perception of overall skin sensitivity was well correlated to perceptions of sensitivity of face or body skin in a prior study (weighted kappa value for agreement for general and facial skin or body skin 0.51 and 0.57 , respectively), while agreement between the perception of sensitive skin overall and that of genital skin sensitivity was not (weighted kappa value $0.28 \%$ ) [1]. An association between incontinence and genital sensitivity was also observed), between ethnicity (African American) and genital sensitivity, and between gender (higher number of women) and genital sensitivity, while no association were observed between any of these parameters and sensitivity at the face or other non-genital sites [1].

The questionnaire presented to respondents in both US and China was identical. It is therefore likely that the differences observed from the two studies can be attributed to regional or cultural differences, most likely the fact that individuals in China and eastern hemisphere countries are in general much more reserved when talking about their genitalia as compared to the US or Europe. Talking about the genital area may be taboo in China compared to the US and European nations where it can be talked about freely. Also in the US, countless products targeted for sensitive skin has created the perception that sensitive skin is fashionable [1].

\subsection{Age Distribution}

In our previous study conducted in Cincinnati, we noticed a distinct correlation between age and genital sensitivity. As respondents age, their skin sensitivity increases. Fifty-three percent of respondents younger than 30 years old claimed to have sensitive genital skin, compared to $55 \%$ of respondent between $31-39$ years old, $58 \%$ of respondents between 40 - 49 years old, and $66 \%$ of respondents older than 50 years old [1]. The Chinese population may have shown a slight increase in genital skin sensitivity but because the percentage of respondents claiming genital sensitivity was so low that it is not possible to conclude that there is a statistically significant correlation between age and genital sensitivity.

The age distribution did not show any differences in degree of sensitive skin, but it may have been difficult to judge the distribution of those that were sensitive for body and genital skin due to the high percentage of respondents who claimed to be not sensitive. The data though, for respondents not sensitive of the body and genitals was very similar in all age groups.

\subsection{Factors Affecting Skin Sensitivity}

Subjects with sensitive skin consistently report skin sensitivity to a variety of factors, including topical products, weather conditions, exposure to rough fabrics or paper products, stress, and the hormones that regulate the menstrual cycle (Figure 3). Weather is an important trigger for sensitive skin, a finding borne out in numerous studies on different continents (Table 4).

Our previous US study had similar findings. Adverse reaction to products accounted $50 \%$ of the causes of sen- 


\section{Triggers}

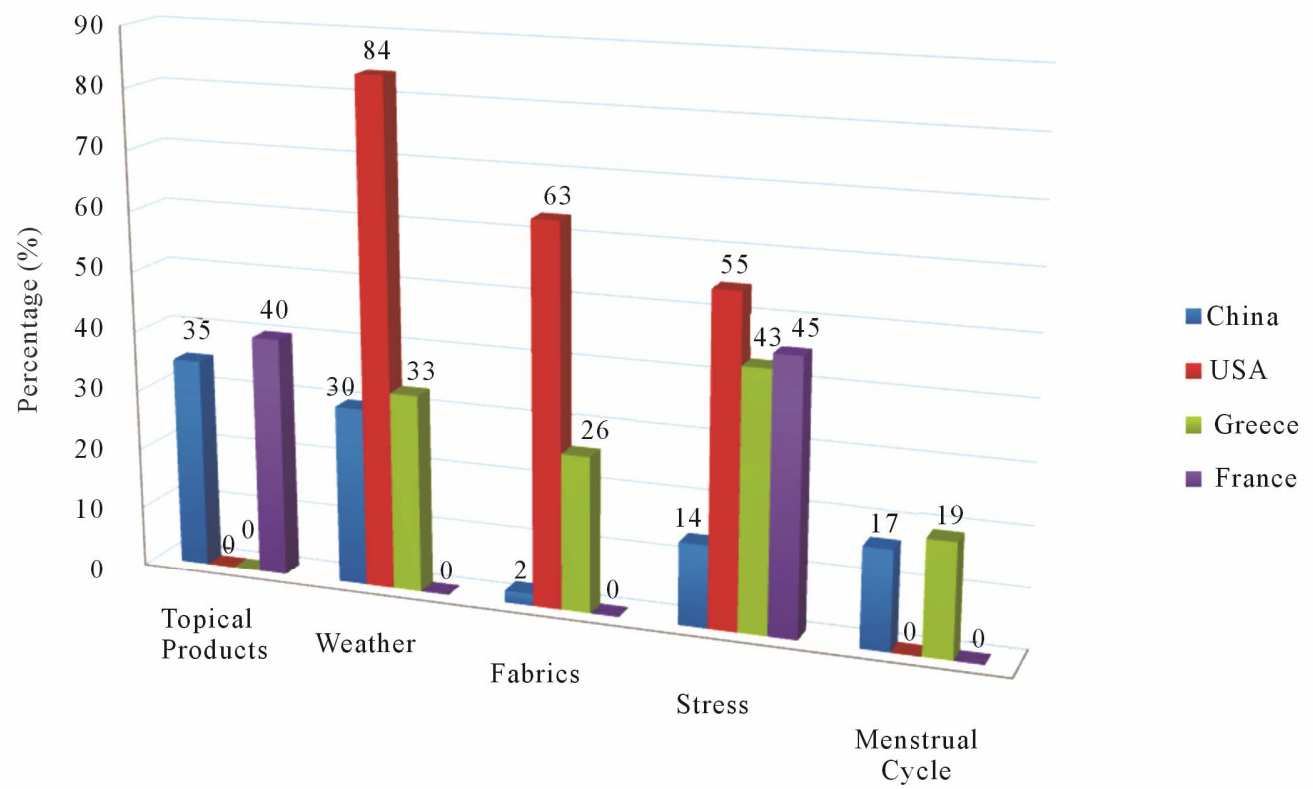

Figure 3. Sensitive skin triggers $(\%)$.

Table 4. Percentages of people who report skin sensitivity to specific weather conditions.

\begin{tabular}{|c|c|c|c|c|c|c|c|c|c|}
\hline \multirow[b]{2}{*}{ Country } & \multirow[b]{2}{*}{ Year $^{*}$} & \multirow[b]{2}{*}{ Population } & \multirow[b]{2}{*}{ Sun } & \multirow[b]{2}{*}{ Heat } & \multicolumn{3}{|c|}{ Weather condition (\%) } & \multirow[b]{2}{*}{ Humidity } & \multirow[b]{2}{*}{ Reference } \\
\hline & & & & & Cold & Dry & Wind & & \\
\hline China & 2009 & $\begin{array}{l}\mathrm{F} \\
18-65 \text { years } \\
\mathrm{N}=408\end{array}$ & 34.5 & 31.2 & 19.2 & 20.5 & 21.1 & 14.7 & Farage current study \\
\hline USA & 2009 & $\begin{array}{l}\mathrm{F} \\
\text { Mean age } 35.1 \mathrm{yrs} \\
\mathrm{N}=869\end{array}$ & 78.4 & 58.7 & 83.9 & 72.9 & 65.0 & 39.9 & {$[11]$} \\
\hline Greece & 2008 & $\begin{array}{l}\mathrm{F} \\
18-45 \mathrm{yrs} \\
\mathrm{N}=25\end{array}$ & NA & 20.0 & 33.0 & 38.0 & 25.0 & 16.0 & {$[17]$} \\
\hline USA & 2006 & $\begin{array}{l}\mathrm{M} \text { and } \mathrm{F} \\
\text { Mean age } \\
39(\mathrm{M}) \text { and } 35.1(\mathrm{~F}) \mathrm{yrs} \\
\mathrm{N}=1032 \\
(163 \mathrm{M}, 869 \mathrm{~F})\end{array}$ & 77.0 & 55.0 & 81.0 & 71.0 & 65.0 & 37.0 & {$[12]$} \\
\hline France & 2004-2005 & $\begin{array}{l}\mathrm{F} \\
18-85 \mathrm{yrs} \\
\mathrm{N}=400\end{array}$ & 50.8 & 27.9 & 65.6 & NA & 41.8 & NA & {$[18]$} \\
\hline France & $\begin{array}{l}\text { March } \\
2004\end{array}$ & $\begin{array}{l}M \text { and } F \\
\geq 15 \text { yrs } \\
N=1006\end{array}$ & 54.6 & NA & 60.2 & 41.1 & 48.9 & NA & {$[2]$} \\
\hline France & $\begin{array}{l}\text { July } \\
2004\end{array}$ & $\begin{array}{l}M \text { and } F \\
\geq 15 \text { yrs } \\
N=1001\end{array}$ & 47.6 & NA & 57.8 & 35.0 & 42.3 & NA & [5] \\
\hline Italy & 2004 & $\begin{array}{l}F \\
18-80 y r s \\
N=1850\end{array}$ & NA & 49.4 & 54.4 & NA & 54.4 & NA & [19] \\
\hline USA & 2002 & $\begin{array}{l}\mathrm{F} \\
18-54 \mathrm{yrs} \\
\mathrm{N}=811\end{array}$ & 68.3 & NA & 60.2 & NA & 61.7 & NA & {$[22]$} \\
\hline
\end{tabular}

$\mathrm{F}=$ Female, $\mathrm{M}=$ Male, $\mathrm{NA}=$ Data not available; "Year of publication. 
sitive skin in the US, while in China it was $51 \%$ when the three body sites were combined. Weather conditions accounted for $35 \%$ in US [12]. In China, when the three body sites were combined, weather accounted for $33 \%$. These figures were adjusted to only include respondents who claimed to have sensitive skin. Interviewees were asked about effects environmental factors on skin sensitivity. The results are dramatically different from the US study, as can be expected since individuals in China have a smaller overall perception of sensitive skin. One finding that was particularly interesting was that in the US cold and hot weather caused skin irritation in $83.9 \%$ and $58.7 \%$ of sensitive skin sufferers, respectively, while in China the sensitivities were reversed. In China hot weather caused more irritation than cold weather, $31.2 \%$ and $19.2 \%$ respectively. Studies in the largely Caucasian population of France, interestingly, conducted 4 months apart (March and July) similarly found higher percentages of sensitive skin in winter months than in the summer [2].

Skin sensitivity related to topical products confirmed the general findings of lower prevalence of skin sensitivity in China, despite the fact that topical products ostensibly carry a high risk of causing irritation. Soap in China does not seem to cause much irritation, while in the US, Greece and France they are some of the worst offenders (Figure 1).

Allergies and hereditary causes could not be assessed due to the low number positive responses $6 \%$ and $4 \%$ respectively.

\subsection{Duration of Skin Sensitivity}

Respondents were also asked how long they have had sensitive skin; most answers were less than 6 months, 1 to 5 years, and 10 years or more. In the US survey $42 \%$ of the individuals responded that they had it for greater than 10 years, while only $1 \%$ claimed to have had the sensitive skin for less than 6 months. After adjusting for the individuals who were not sensitive, we have $62 \%$ of respondents in the US with sensitive skin having had it for more than 10 years compared to only $20 \%$ for the Chinese population [12]. When comparing the less than 6 months group, we have $1.5 \%$ of Americans compared to $38 \%$ of Chinese [12]. Also when asked about changes in severity of sensitive skin, the findings between the US and China were dramatically different [12]. The degree of severity of sensitive skin is decreasing in China where the US survey shows that individuals feel that the severity is increasing. Thirty one percent of the responders in the US survey claimed that they are either a little or much more sensitive now [12]. In China 3\% stated that they are either a little or much more sensitive facial skin now, $2 \%$ for sensitive body skin, and less than $1 \%$ for sensitive genital skin. Even though there were many re- spondents who claimed to have sensitive skin for less than 6 months. between 1 and 5 years, or 10 years or more, but there were very few who claimed to have sensitive skin between $6-11$ months or $6-10$ years. Data for China came by combining data from the three body sites.

The meaning of sensitive skin in the East differs from that of the West, which may contribute to the higher prevalence observed in the West as compared to China. In China sensitive skin is considered an acute and transitory condition while in the US it is viewed as more of a permanent condition causing chronic irritation. Therefore there may have been respondents in China who claimed not to have sensitive skin who may have had it in the past. The number of individuals who had sensitive skin in the past were not accounted for because we understood the cultural differences in sensitive skin perception only after the completion of the study. Sensitive skin in the past, therefore, was not included in the questionnaire. In general, since sensitive skin is not as well defined as other disease states, different cultures interpret or understand sensitive skin differently.

\section{Conclusions}

When we compared this study to the one conducted in the US we were surprised to find much lower percentages of individuals claiming to have overall sensitive skin, but especially sensitive skin of the body and genitals. The percent of respondents who claimed to have sensitive skin was $41.4 \%$, while $38 \%$ claimed to have sensitive facial skin, $16 \%$ claimed to have sensitive skin of the body, and only $7 \%$ claimed to have sensitive genital skin.

Even though the sensitive skin figures were lower than in the US population we still noticed relatively similar results when we looked at what causes and exacerbates sensitive skin. Weather conditions were stated as the most likely cause of sensitive skin $(32.7 \%)$, then sensory irritation $(25.5 \%)$, visual irritation $(25.5 \%)$, and rough fabrics $(12.0 \%)$. If sensory and visual irritation were combined, the primary cause of sensitive skin would be adverse reactions to products. Of the weather conditions, the sun and hot weather were considered to be the worst offenders.

There were a larger percentage of respondents who claimed to have sensitive skin for less than 6 months as compared to approximately half that claiming to have had it for greater than 10 years. Most respondents also claimed that their severity of sensitive skin was also getting better over time, especially those that claimed to have slightly sensitive skin. Only two respondents claimed to have much more sensitive skin now.

As discussed, numerous interpersonal variables can affect evaluations of skin sensitivity such as lifestyle pa- 
rameters including time spent outdoors, forms of indoor climate control, and occupational or leisure activities. In addition, slight variations in the wording of surveys can cause substantial differences in the survey results obtained, i.e. asking subjects whether they experience redness or sensory effects rather than asking if skin is "easily irritated".

One debated factor in skin sensitivity is that the influence that cultural components, including advertising, can play. Manufacturers of skin products, over the time period that the rise in skin sensitivity in western cultures has risen, have increasingly marketed products targeted for sensitive skin. An increase in perceived skin sensitivity in men, particularly (although one recent study found the perception of sensitive skin in men and women to be virtually equal) [1].

A recent epidemiological study in Europe would seem to confirm a cultural component. A comparison of selfreported skin sensitivity in eight European countries found dramatic differences between national populations that are genetically very similar (Portugal, Italy, and Spain, for example, reporting $80 \%$ to $90 \%$ of their population as experiencing at least some sensitivity; while Germany, Belgium, and Switzerland reported just a little more than half), an unexpected finding that the authors attributed primarily to substantially more fashion and beauty-related advertising in specific European countries [3].

The finding that substantially fewer Chinese women (residents of a developing country with putatively less aggressive advertising of products targeted for sensitive skin), claim skin sensitivity than their counterparts in the west would seem to bolster the supposition that sensitive skin has at least some cultural component.

However, this study relied solely on consumer claims of skin sensitivity without independent physiological verification; much progress has been made over the last decade in unraveling a genuine physiological basis for skin sensitivity as well [15]. Much work remains to be done in order to achieve a satisfactory understanding of both dermatological and psychosocial aspects of sensitive skin in the global context.

\section{Acknowledgements}

The authors would like to thank for Dr. Kenneth W. Miller and Mr. Ron Visscher for the review and input on this manuscript; Mr. Sugar Shukla for his critical work on the technical draft revisions and Ms. Wendy Wippel and Ms. Zeinab Schwen (Strategic Regulatory Consulting) for technical writing assistance.

\section{REFERENCES}

[1] M. A. Farage, "How Do Perceptions of Sensitive Skin
Differ at Different Anatomical Sites? An Epidemiological Study," Clinical and Experimental Dermatology, Vol. 38, No. 8, 2009, pp. e521-e530. doi:10.1111/j.1365-2230.2009.03487.x

[2] L. Misery, E. Myon, N. Martin, S. Consoli, T. Nocera and C. Taieb, "Sensitive Skin: Epidemiological Approach and Impact on Quality of Life in France," In: E. Berardesca, J. W. Fluhr and H. I. Maibach, Eds., Sensitive Skin Syndrome, Taylor \& Francis, New York, 2006, pp. 181-191.

[3] L. Misery, S. Boussetta, T. Nocera, N. Perez-Cullell and C. Taieb, "Sensitive Skin in Europe," Journal of the European Academy of Dermatology and Venereology, Vol. 23, No. 4, 2009, pp. 376-381.

doi:10.1111/j.1468-3083.2008.03037.x

[4] C. M. Willis, S. Shaw, O. De Lacharrière, M. Baverel, L. Reiche, R. Jourdain, P. Bastien and J. D. Wilkinson, "Sensitive Skin: An Epidemiological Study," The British Journal of Dermatology, Vol. 145, No. 2, 2001, pp. 258-263. doi:10.1046/j.1365-2133.2001.04343.x

[5] L. Misery, E. Myon, N. Martin, S. Consoli, S. Boussetta, T. Nocera and C. Taieb, "Sensitive Skin: Psychological Effects and Seasonal Changes," Journal of the European Academy of Dermatology and Venereology, Vol. 21, No. 5, 2007, pp. 620-628.

[6] H. Löffler, "Contact Allergy and Sensitive Skin," In: E. Berardesca, J. Fluhr and H. Maibach, Eds., Sensitive Skin Syndrome, Taylor and Francis, New York, 2006, pp. 225235.

[7] M. A. Farage, K. W. Miller, P. Elsner and H. I. Maibach, "Intrinsic and Extrinsic Factors in Skin Ageing: A Review," International Journal of Cosmetic Science, Vol. 30, No. 2, 2008, pp. 87-95. doi:10.1111/j.1468-2494.2007.00415.x

[8] B. G. Green, "Measurement of Sensory Irritation of the Skin," American Journal of Contact Dermatitis, Vol. 11, No. 3, 2000, pp. 170-180. doi:10.1053/ajcd.2000.7185

[9] M. B. Britz and H. I. Maibach, "Human Cutaneous Vulvar Reactivity to Irritants," Contact Dermatitis, Vol. 5, No. 6, 1979, pp. 375-377. doi:10.1111/j.1600-0536.1979.tb04908.x

[10] P. Elsner, D. Wilhelm and H. I. Maibach, "Sodium Lauryl Sulfate-Induced Irritant Contact Dermatitis in Vulvar and Forearm Skin of Premenopausal and Postmenopausal Women," Journal of the American Academy of Dermatology, Vol. 23, No. 4, 1990, pp. 648-652.

[11] M. A. Farage, "Does Sensitive Skin Differ between Men and Women?" Cutaneous and Ocular Toxicology, Vol. 29, No. 3, 2010, pp. 153-163. doi:10.3109/15569521003774990

[12] M. A. Farage, "Perceptions of Sensitive Skin: Changes in Perceived Severity and Associations with Environmental Causes," Contact Dermatitis, Vol. 59, No. 4, 2008, pp. 226-232. doi:10.1111/j.1600-0536.2008.01398.x

[13] M. A. Farage and H. I. Maibach, "Sensitive Skin: Closing in on a Physiological Cause," Contact Dermatitis, Vol. 62, No. 3, 2010, pp. 137-149. doi:10.1111/j.1600-0536.2009.01697.x

[14] M. A. Farage, A. Katsarou and H. I. Maibach, "Sensory, 
Clinical and Physiological Factors in Sensitive Skin: A Review," Contact Dermatitis, Vol. 55, No. 1, 2006, pp. 1-14. doi:10.1111/j.0105-1873.2006.00886.x

[15] E. Berardesca, J. Fluhr and H. Maibach, "Sensitive Skin Syndrome," Taylor and Francis, New York, 2006.

[16] A. Johnson and D. Page, "Making Sense of Sensitive Skin," Congress of the International Federation of Society of Cosmetic Chemists, Yokohama, 13-16 October 1992.

[17] M. A. Farage, P. Bowtell and A. Katsarou, "Self-Diagnosed Sensitive Skin in Women with Clinically Diagnosed Atopic Dermatitis," Clinical Medicine: Dermatology, Vol. 2, 2008, pp. 21-28.

[18] C. Saint-Martory, A. M. Roguedas-Contios, V. Sibaud, A. Degouy, A. M. Schmitt and L. Misery, "Sensitive Skin Is Not Limited to the Face," The British Journal of Dermatology, Vol. 158, No. 1, 2008, pp. 130-133.

[19] A. Sparavigna, A. Di Pietro and M. Setaro, "Healthy Skin: Significance and Results of an Italian Study on Healthy Population with Particular Regard to 'Sensitive' Skin," International Journal of Cosmetic Science, Vol. 27, No. 6, 2005, pp. 327-331. doi:10.1111/j.1467-2494.2005.00287.x
[20] F. Morizot, C. Guinot, S. Lopez, I. Le Fur, E. Tschachler and C. Wood, "Sensitive Skin: Analysis of Symptoms, Perceived Causes and Possible Mechanisms," Cosmetics \& Toiletries, Vol. 115, 2000, pp. 83-89.

[21] C. Guinot, D. Malvy, E. Mauger, K. Ezzedine, J. Latreille, L. Ambroisine, M. Tenenhaus, P. Préziosi, F. Morizot, P. Galan, S. Hercberg and E. Tschachler, "Self-Reported Skin Sensitivity in a General Adult Population in France: Data of the SU.VI.MAX Cohort," Journal of the European Academy of Dermatology and Venereology, Vol. 20, No. 4, 2006, pp. 380-390. doi:10.1111/j.1468-3083.2006.01455.x

[22] R. Jourdain, O. de Lacharrière, P. Bastien and H. I. Maibach, "Ethnic Variations in Self-Perceived Sensitive Skin: Epidemiological Survey," Contact Dermatitis, Vol. 46, No. 3, 2002, pp. 162-169. doi:10.1034/j.1600-0536.2002.460307.x

[23] L. Misery, V. Sibaud, M. Ambronati, G. Macy, S. Boussetta and C. Taieb, "Sensitive Scalp: Does This Condition Exist? An Epidemiological Study," Contact Dermatitis, Vol. 58, No. 4, 2008, pp. 234-238. doi:10.1111/j.1600-0536.2007.01288.x 